\title{
Administração estratégica em agência de viagens e turismo: uma aplicação do Balanced Scorecard (BSC)
}

\section{Strategic management in travel and tourism agency: an application of the Balanced Scorecard (BSC)}

\author{
José Elmar Feger (FEGER, J. E.) \\ Paulo André Alves (ALVES, P. A.) ${ }^{* *}$
}

RESUMO - O debate no que tange a administração estratégica tem intensificado a discussão sobre a necessidade de melhorar os níveis de efetividade visto que corresponde ao conjunto de decisões que determinam o futuro da organização. O recorte abordado nesta investigação tem maior aderência à fase de implementação e controle no transcurso da gestão estratégica discutindo-se a utilização do instrumento balanced scorecard (BSC), para o gerenciamento estratégico de uma agência de viagens localizada em Curitiba (Paraná, Brasil). O objetivo central da investigação foi descrever o processo e o resultado alcançado pela referida agência ao implementar o seu planejamento estratégico por meio do BSC. Diante da especificidade da pesquisa, para o alcance dos seus objetivos, toma-se por método de coleta e análise de dados a observação participante, considerando que ela auxilia analisar a realidade social, tentando captar os conflitos e tensões existentes no processo de promover as mudanças necessárias. Com base no estudo realizado no ano de 2013, verificou-se que com a aplicação da ferramenta, obteve-se uma melhoria na gestão, aumento da produtividade representada pela redução de custos em $29,4 \%$ e a melhoria da qualidade dos serviços com apenas $0,9 \%$ de reclamações dos clientes atendidos.

Palavras chave: Balanced Scorecard; Agência de turismo; Administração estratégica.

ABSTRACT - The debate related to Strategic Management has intensified the discussion about the need of improving the effectiveness levels which corresponds to the set of decisions that determine the organization future. The fragment approached in this research has greater adherence to the implementation and control phase of strategic management with the use of the Balanced Scorecard tool (BSC), for the strategic management of a travel agency located in Curitiba (Paraná, Brazil). The main objective of this research was to describe the process and the result achieved by this agency in the implementation of its strategic planning using the BSC. Since this research is very

\footnotetext{
* Formação: Graduação em Administração pela Universidade do Contestado (UnC), Especialização em Turismo pela Universidade do Oeste de Santa Catarina (UNOESC), Mestrado em Desenvolvimento Regional pela Universidade Regional de Blumenau (FURB) e Doutorado em Desenvolvimento Regional pela Universidade de Santa Crus do Sul/RS (UNISC). Atividade profissional: Professor e Pesquisador do Programa de Mestrado em Turismo da Universidade Federal do Paraná (UFPR). Endereço físico para correspondência: Rua Mário Bueno Sobrinho, 68 SB2, Bairro Uberaba. CEP 81530-525 - Curitiba Paraná (Brasil). E-mail: elmar.josefeger@gmail.com

** Formação: Graduação em Administração pela Sociedade de Paranaense de Ensino e Informática (SPEI), Especialização em Gestão Empresarial pelo Instituto Brasileiro de Pós-Graduação e Extensão (IBPEX) e MBA em inteligência de negócios pela Universidade Federal do Paraná (UFPR). Atividade profissional: Professor do Instituto de Ensino Superior de Londrina, Faculdade Educacional de Colombo. Endereço físico para correspondência: Rua Dorval Ceccon, Bairro Fátima, s./n. CEP 83405030 Colombo - Paraná (Brasil). E-mail: admpauloandrealves@hotmail.com
} 
specific, for the achievement of its goals, it was used as the methodology of collecting and analyzing data, the participant observation, considering that it helps to analyze the social reality, trying to capture the conflicts and tensions in the process in order to promote the necessary changes. Based on the performed study in 2013, it has found that with the application of BSC tool, it was obtained some improvement in the management, increasing in productivity represented by the cost reduction in $29.4 \%$ and improvement of service quality with only $0.9 \%$ complaints of clients served by the agengy.

Key words: Balanced Scorecard; Tourism agency; Strategic management. 


\section{INTRODUÇÃO}

$\mathrm{O}$ planejamento estratégico ganha corpo nas últimas décadas do século $\mathrm{XX}$ como procedimento para ajustar a empresa ao seu ambiente concorrencial (PORTER, 1989; OLIVEIRA, 2011). No campo do turismo essa prática é assimilada não só para elaborar estratégias empresariais, mas também, de destinos turísticos (SWARBROOKE, 2000; RUIZ e GÂNDARA, 2013).

O debate no que tange ao tema tem evoluído e discute-se a necessidade de melhorar os níveis de gestão estratégica, visto que corresponde ao conjunto de decisões que determinam o futuro da organização (WRIGHT; KROLL; PARNELL, 2011). A necessidade de gerenciamento da estratégia é proporcional ao crescimento da organização e envolve desde a análise do ambiente interno e externo, a formulação das estratégias, a sua implementação e a respectiva avaliação e controle (THOMPSON; STRICKLAND, 2000).

O tema abordado nesta investigação tem maior aderência à fase de implementação e controle no transcurso da gestão estratégica discutindo-se a utilização do instrumento desenvolvido por Kaplan e Norton (1997) o Balanced Scorecard (BSC), para o gerenciamento estratégico de uma agência de viagens localizada em Curitiba (Paraná, Brasil).

Justifica-se o foco de estudo neste recorte, visto que as agências de viagens enfrentam desafios para permanecerem lucrativas, especialmente devido a mudanças ocorridas no ambiente mercadológico diante da propagação do uso das tecnologias de informação e comunicação (DANTAS; GOSLING; COELHO, 2013). Concomitantemente, ocorrem mudanças devido a própria dinâmica do mercado, considerando que em 2004 as agências de turismo no Brasil apresentaram um crescimento de $20,01 \%$ em seu faturamento. Essa situação permaneceu mais ou menos estável até 2008 quando ocorreu uma inflexão desta tendência, visto que no ano de 2009 adveio um decréscimo de 4,70\% (BRASIL, 2011).

Como pode ser depreendido dos fatos preteritamente descritos, o momento de negócios atual é complexo, ambíguo e paradoxal caracterizado por altos níveis de imprevisibilidade e intensificação da competição. Este cenário tem levado a um processo de reorganização, abarcando a dispersão e fragmentação das atividades 
econômicas, sociais, culturais, demográficas, ecológicas, políticas e legais, dentre outras (ANDRADE et al., 2012). Sopesando-se esta instabilidade no mercado, a implantação de ferramenta de administração estratégica para operacionalizar os objetivos empresariais se constitui em questão relevante. Todavia, grande parte dos estudos no campo do turismo está voltada para a formulação de estratégias, e não no seu encadeamento de implementação e controle. Assim, justifica-se a ampliação de estudos que tratem da aplicação de ferramentas que auxiliam na consolidação das estratégias empresariais, a exemplo do BSC.

Diante do exposto, foi desenvolvido um estudo de caso em uma agência de viagens localizada em Curitiba, Paraná, a qual estava atuando há mais de 25 anos no mercado turístico. Identificou-se possuir em seu portfólio serviços de agenciamento de viagens a lazer ou negócios, auxílio para vistos consulares, locação de veículos e artigos para viagem. Dada a sua estrutura e movimento enquadrava-se como uma empresa de médio porte, adotando-se o critério do SEBRAE (Serviço de Apoio às Micro e Pequenas Empresas) quanto ao número de empregados, pois possuía 65 colaboradores registrados. No que tange ao faturamento bruto anual estava auferindo receita média de R \$ 30 milhões. No presente artigo, passa-se a denominar a empresa investigada como Agência X, dada a solicitação para manter sua identidade em sigilo.

Assim, estabeleceu-se como objetivo central do estudo, descrever o processo e o resultado alcançado pela Agência $\mathrm{X}$ ao implementar o seu planejamento estratégico por meio do Balanced Scorecard.

Desdobrando-se este objetivo geral em específicos, pretendeu-se (1) aprofundar conhecimentos teóricos sobre o BSC; (2) identificar as fases necessárias à adaptação da referida ferramenta para aplicação em uma agência de viagens; (3) identificar os procedimentos adotados para a aplicação do BSC como instrumento para o gerenciamento estratégico da agência de viagens X.

A estrutura do texto contempla esta breve introdução, seguindo-se com a fundamentação teórica inerente ao BSC, na sequência apresenta-se a metodologia utilizada e a apresentação dos dados colhidos, finalizando-se com as considerações finais. 


\section{AGÊNCIAS DE VIAGENS E ADMINISTRAÇÃO ESTRATÉGICA}

O Turismo é um setor econômico dinâmico, globalizado e fortemente influenciado por diversas variáveis, tais como, o nível de renda per capita, taxa de câmbio, crescimento da economia, nível de crédito, taxa de juros, entre outras (BRASIL, 2011). Enquanto atividade produtiva demanda a participação de diversas empresas que viabilizem a sua prática; é preciso uma rede integrada de empresas que prestem os diversos serviços necessários ao turista tais como hospedagem, transporte, alimentação e intermediação de pacotes turísticos (BORGES; GUARDIA, 2012).

Em vista do contexto em que se pauta o presente estudo, toma-se como unidade de análise o elemento de intermediação (GORNI; DREHER; MACHADO, 2009; ANJOS et al., 2011) entre as demais empresas que atuam na prática do turismo, as agências de viagens. A finalidade destas corporações no turismo, consiste em distribuir os produtos da referida rede de prestadores de serviços (BORGES; GUARDIA, 2012). Asseveram os autores, que elas organizam os pacotes de viagens nos quais estão imbricados os serviços de hospedagem, alimentação, transporte e entretenimento, funcionando como um agente facilitador que intermedia os fornecedores $\mathrm{e}$ consumidores (BORGES; GUARDIA, 2012).

Os serviços prestados pelas agências de viagens possuem características e especificidades peculiares. Primeiramente são produtos intangíveis, ponderando-se que o consumidor não tem como tocar ou visualizar previamente ao consumo do serviço. Além disso, são produtos criados e consumidos simultaneamente e de forma inseparável. Por fim, não podem ser estocados, ou seja, são produtos perecíveis (GORNI; DREHER; MACHADO, 2009).

Dadas as mudanças ocorridas na sociedade, especialmente com a ampliação do uso de sofisticados processos de comunicação por meio das tecnologias de informação, a faina das agências sofreu um profundo impacto, visto que o usuário pode acessar diretamente aos fornecedores da rede de empresas turísticas, prescindindo do serviço de intermediação (MENEZES; STAXHYN, 2011). Para os referidos autores, tais mudanças provocaram a necessidade de reestruturação dos serviços fornecidos pelas agências, as quais precisam agregar valor a seu trabalho, constituindo-se como consultores de viagens, atuando como conselheiros aos viajantes, tarefa que os serviços informatizados ainda não conseguem exercer. Nesta mesma linha de pensamento 
Rangel e Braga (2012) mencionam que as novas tecnologias do mercado virtual (internet) oferecem aos clientes a possibilidade de compra de suas passagens diretamente no site das companhias aéreas com preços de tarifas reduzidas, eliminando os valores de comissões repassados as agências de turismo pelas companhias aéreas interferindo no seu faturamento. Todavia, enfatizam que, essas facilidades oferecem economia, comodidade, rapidez e agilidade, mas, não conseguem atender a demanda de situações que precisam combinar traslado ou compatibilização de horários e datas, roteiro e itinerários compartilhados. Nestes casos, o consumidor precisará de uma agência de turismo que poderá lhe oferecer este serviço com maior segurança.

Aliado a isso, Borges e Guardia (2012) afirmam que tais facilidades agregadas ao processo de globalização, acarretaram que o consumidor passasse a ter mais acesso a informações e conhecimento sobre as atividades desenvolvidas pelos prestadores de serviços de turismo. Consequentemente o nível de exigência por parte do usuário e a concorrência de mercado aumentaram, influenciando na forma de atuação empresarial, precisamente das agências de viagens. Significa dizer, que em tempos de globalização, internet e avanço tecnológico torna-se necessário buscar soluções eficientes e eficazes para a sustentabilidade da empresa (ANJOS et al., 2011).

Neste cenário as agências de viagens precisam de estratégias inovadoras a fim de assegurar sua permanência e crescimento no mercado. O planejamento é requerido a fim de agregar valor às atividades que desempenham, inclusive com uso de tecnologia e ferramentas que facilitem a administração estratégica (WRIGHT; KROLL; PARNELL, 2011). Concomitante a isso, carece considerar o desenvolvimento dos recursos humanos (ativos intangíveis) e difusão tecnológica para este segmento. O fator humano é considerado um aspecto importante para que uma organização aufira competitividade, especialmente no que tange a qualificação, produtividade e flexibilidade o que conduz a necessidade de considerá-lo no planejamento estratégico (FERRAZ, KUPFER, HAGUENAUER, 1995; WRIGHT, KROLL, PARNELL, 2011).

No âmbito do presente estudo, concebe-se o termo estratégia em sua conotação adaptada do contexto militar (a arte do general em conduzir seu exército à vitória da guerra) para a administração empregando o seu uso com o significado de "ser aquilo que leva uma empresa a vencer a concorrência do mercado" (SOUTO-MAIOR, 2012, p. 126). 
A fim de lograr êxito na competição pelo mercado, como já dito, é requerido o planejamento, que segundo Oliveira (2011), é um processo de criação de um futuro desejado por meio da definição de ações efetivas para torná-lo realidade. $\mathrm{O}$ planejamento é considerado estratégico para Souto-Maior (2012) quando é capaz de desenvolver estratégias de enfrentamento da concorrência e do mercado, sendo que o envolvimento do proprietário é determinante para tal.

Para Kaplan e Norton (1997), uma empresa orientada para a estratégia aplica princípios gerenciais que buscam traduzir em termos operacionais as suas estratégias transformando-as em coletivas (de todos) e num processo contínuo, que esteja alinhado à organização e vice-versa, com a mobilização a partir da liderança executiva. Para os autores, um bom planejamento deve proporcionar a eficiência, eficácia e efetividade para a empresa, maximizando os resultados e minimizando suas deficiências, transformando as aspirações em realidade.

A criação de valor está migrando da gestão de ativos tangíveis para a gestão de estratégias baseadas no conhecimento, que exploram os ativos intangíveis da organização: relacionamento com os clientes, produtos e serviços inovadores, tecnologia da informação suportada por banco de dados, além de capacidades, habilidades e motivação dos empregados (KAPLAN; NORTON, 2001). Assim, há necessidade de mensuração não só dos indicadores financeiros empregados até recentemente, mas também, das estratégias aplicadas, bem como, de outros vetores voltados para o desempenho.

Significa dizer que desenvolver capacidades para o futuro seria um processo de criação de valor por meio, dos ativos intangíveis (KAPLAN; NORTON, 2001). Por conseguinte, surgiu a necessidade de uma ferramenta de planejamento estratégico que proporcionasse o equilíbrio. Emergiu a demanda por um método no qual fosse possível se manter em curso com condições de alcançar o ponto onde se deseja chegar no futuro. Para esse fim, Kaplan e Norton (2001) criaram um programa de mensuração de performance denominado Balanced Scorecard (BSC) com o propósito de fornecer ferramentas para descrever o processo de criação de valor para os clientes tendo por princípio os ativos intangíveis. Além disso, uma metodologia de mensuração da performance da empresa que permite ajustá-la ao que se pretende ser no futuro, conceito que no contexto da gestão estratégica denomina-se visão. 
Dessa forma, Kaplan e Norton (2001) definiram que uma estratégia voltada para a visão da empresa deverá estar alicerçada em quatro perspectivas que atuam de forma cíclica, onde em cada uma deverá existir objetivos estratégicos, metas específicas, medidas e plano de ação. As quatro perspectivas estão alinhadas de maneira sinérgica e a construção do BSC desta maneira deve traduzir a estratégia da empresa e o caminho a percorrer para atingir o objetivo (OLVE; ROY; WETTER, 2001).

A perspectiva financeira do BSC é mantida visto que as medidas deste quesito indicam o desempenho dos resultados econômicos a cada estratégia implementada e executada. No modelo adotado pelo BSC esta concepção está associada a lucratividade e aborda questões de como se deve apresentar para os acionistas da empresa (KAPLAN; NORTON, 1997).

A outra perspectiva focada no cliente proporciona a empresa a identificação do mercado e segmento de clientes no qual a companhia irá competir e as respectivas "medidas de desempenho nesse(s) mercado-alvo". Neste âmbito deverão estar especificadas as "propostas de valor que a empresa oferecerá aos clientes desses segmentos" permitindo a articulação de estratégicas focadas nos clientes e no mercado que proporcionem aumento da lucratividade financeira futura (KAPLAN; NORTON, 1997, p. 26).

Os processos internos, a terceira perspectiva, alude que a empresa necessita identificar os pontos críticos de seus procedimentos realizados internamente voltados para atender ao cliente. Esses aspectos requerem ser trabalhados e otimizados para alcançar qualidade e excelência com maior impacto na satisfação do cliente. Supõe-se que a melhoria desses aspectos contribui para o alcance do objetivo financeiro da empresa no momento atual e no futuro. Vale salientar que nesta ótica será possível definir novos processos a serem implementados para atingir os objetivos propostos que atribuam maior capacidade de oferecer valor aos clientes o que se pode chamar de inovação dos processos internos (KAPLAN; NORTON, 1997).

A última perspectiva abordada no BSC, segundo os mesmos autores, corresponde ao aprendizado e crescimento com a finalidade de determinar qual a infraestrutura (pessoas, sistema e procedimentos organizacionais) requerida à empresa, de maneira a promover o crescimento e melhorias de longo prazo. Nesse sentido, demanda diagnosticar as necessidades da empresa em relação aos seus recursos 
humanos, sistema, tecnologia da informação, procedimentos e rotinas organizacionais que deverão ser otimizados para alcançar um desempenho inovador.

Em síntese o BSC associa o equilíbrio (balanced) entre as medidas e o conjunto de operações que serão selecionadas em uma quantidade suficientemente balanceada para manter o percurso a fim de alcançar o desenvolvimento futuro e os resultados esperados. O scorecard é o método que auxilia a criar este equilíbrio entre os vários elementos da performance estratégica e operacional por meio do registro de resultados alcançados assegurando a obtenção dos objetivos que conduzem a organização em direção ao futuro por ela desejado (OLVE; ROY; WETTER, 2001).

Todavia, para a efetividade do BSC é imperativo tomar atenção em relação a dois pontos específicos, a elaboração do mapa estratégico e o monitoramento constante de cada uma das ações ou etapas (HIKAGE; SPINOLA; LAURINDO, 2006). Para Kaplan e Norton (2001), o mapa estratégico corresponde ao desenho arquitetônico que genericamente descreve a estratégia de forma integrada e sistêmica.

A fim de mensurar os resultados e monitorar a implementação das estratégias a partir do mapa estratégico, os autores indicam a utilização de indicadores, que correspondem a "uma medida que resume informações importantes sobre determinado fenômeno" (MALHEIROS; COUTINHO; PHILIPI JÚNIOR, 2012, p. 35). Explicam os autores que é como um "índice" que traduz significado, promovendo a compreensão de algo já definido, em um determinado espaço de tempo, para uma determinada situação, a uma pessoa ou grupo de interesse. Compreende-se o seu significado por meio da informação interpretada e, no contexto da administração estratégica, servem para acompanhar o andamento do processo, obtendo informações importantes para a eficiência, propiciando a organização identificar possíveis problemas e riscos que venham a incorrer (HIKAGE; SPINOLA; LAURINDO, 2006).

Com essas considerações encerra-se a discussão das premissas teóricometodológicas que subsidiam o estudo proposto. 


\section{METODOLOGIA}

O tema da pesquisa envolve a aplicação da ferramenta denominada BSC, que possui, segundo os seus criadores Kaplan e Norton (2001), como principal objetivo auxiliar a gestão na busca do equilíbrio entre os seguintes aspectos organizacionais: objetivos de curto e de longo prazo; medidas financeiras e não financeiras; indicadores de tendências e ocorrências; como também, entre perspectivas interna e externa de desempenho.

O contexto onde ocorreu o estudo foi uma agência de viagens localizada em Curitiba, a Agência X, a qual em detrimento ao crescimento acentuado que auferiu nos últimos anos viu-se diante de um aumento de faturamento bruto, porém, incorria em perda de rentabilidade em relação a concorrência. Diante disso, optou por implementar o BSC como ferramenta de gestão, dando origem ao trabalho cujos resultados aqui são apresentados, que foi elaborado ao longo do ano de 2013, portanto com duração de um ano.

Em virtude da especificidade em que a pesquisa foi proposta, metodologicamente o estudo tomou características próprias. Em primeiro lugar, ao realizar a pesquisa numa organização que se dispunha a implantar o BSC como instrumento de gestão estratégica, a investigação se caracteriza como estudo de caso, segundo os preceitos definidos por Yin (2010). Nesse sentido, para o referido autor, um estudo de caso é adequado quando pretende esclarecer uma decisão ou um conjunto de decisões. Esse preceito teórico coaduna com o propósito da presente investigação visto que seu objetivo é compreender o conjunto de decisões e procedimentos adotados pela organização ao implementar seu planejamento estratégico por meio do BSC. Além disso, justifica-se a seleção de uma única unidade de análise, aceitando-se o argumento de Yin (2010) de que o seu uso poderá contribuir para a formação do conhecimento e da teoria clarificando por que um conjunto de decisões foram tomadas, como elas são implementadas e quais são seus resultados, correspondendo a um conjunto de decisões necessárias para administrar as estratégias da organização por meio do BSC. Além disso, visto que o estudo se realizaria ao longo de doze meses, seria possível medir o desempenho e analisar as modificações ocorridas em períodos distintos, coadunando com a premissa de Yin (2010) ao argumentar que tal pressuposto pode ser válido em 
caso da teoria de interesse especificar como determinadas condições mudam com o tempo, e os intervalos de tempo desejados refletem os estágios em que as mudanças deveriam se revelar. O que também correspondeu aos interesses da pesquisa visto que ao dar andamento às etapas para implantação do BSC, o pesquisador acompanhou a evolução da organização em vários momentos.

Em segundo lugar, o estudo se classifica como qualitativo-descritivo. A pesquisa qualitativa tem por foco o estudo do processo vivenciado pelo sujeito, desta maneira a realidade é construída a partir do referencial dele próprio (QUEIROZ et al., 2007). Embora tenham sido utilizados indicadores numéricos para acompanhar o desempenho da organização analisada ao implantar as estratégias não foram utilizados métodos estatísticos para sua análise e comparação, o que segundo Godoy (1995) mantém a conotação qualitativa. Trata-se, também, de um estudo descritivo visto que a finalidade foi observar, registrar e analisar os fenômenos ou sistemas técnicos relacionados com o fenômeno estudado (MARKONI; LAKATOS, 2006), no caso, a implementação de estratégias por meio do BSC.

Os autores aludem que tanto as pesquisas com abordagem qualitativa (QUEIROZ et al. 2007; MARKONI; LAKATOS 2006; MATTAR 2008), como estudos de caso (YIN 2010; GIL 2002), possuem como característica utilizar um número variado de métodos e instrumentos de coleta de dados, dentre os mais aplicados encontram-se a entrevista em profundidade, a análise de documentos e a observação participante ou não.

Diante disso, em terceiro lugar, para o alcance dos objetivos da presente pesquisa, tomou-se por método de coleta de dados a observação participante, considerando que ela auxilia analisar a realidade social, tentando captar os conflitos e tensões existentes bem como, os grupos sociais que chamam para si a motivação para promover as mudanças necessárias (QUEIROZ et al., 2007).

Nesse caso, a pesquisa participante envolve a interação entre o pesquisador e o meio social que pretende compreender. Dada a interação dos envolvidos no processo, visto que o pesquisador se insere no meio contribui para a modificação tanto do pesquisador como do pesquisado. Diante dessa interação ocorre a mudança do comportamento do grupo observado, tratando-se de uma combinação de trocas de informações e dados, em que o exercício do conhecimento ocorre de uma parte com o 
todo. Nesse sentido, dada a cultura e regras criadas faz com que o efeito seja ao mesmo tempo causa (QUEIROZ et al., 2007). Asseveram os autores que "outro princípio importante na observação é integrar o observador a sua observação, e o conhecedor ao seu conhecimento" (QUEIROZ et al., 2007, p. 278).

No caso desta investigação, o interesse foi compreender o processo de implantação da administração estratégica por meio do BSC. Nesse caso o pesquisador precisou se inserir no ambiente visto que era o conhecedor da ferramenta. Mais precisamente, visto que a participação dos integrantes do contexto da agência $X$ visava a busca de solução para os problemas por meio da observação, descrição e planejamento de ações, a pesquisa se enquadra também como pesquisa-ação, segundo os preceitos de Thiollent (2000) ${ }^{1}$ apud Gori (2006).

Assim, empregou-se a técnica de pesquisa ação, durante todo o processo de diagnóstico, análise, implantação e avaliação. Para este procedimento, adotou-se como ferramenta de interação o ciclo PDCA, instrumento muito utilizado nos programas de qualidade total para promover melhorias contínuas nas organizações (LAS CASAS, 1997). Em cada etapa do processo as atividades eram planejadas em conjunto (Plan), depois executadas (Do), em seguida avaliadas (Check) e promovidas as correções necessárias (Action), sempre ocorrendo a interação entre o pesquisador e representantes da organização. Esse movimento está em acordo com os procedimentos da pesquisaação (THIOLLENT, 2000² apud GORI, 2006), visto que para acompanhar a implementação do BSC o pesquisador promove a participação de integrantes do contexto empresarial na busca de solução dos problemas, observando, descrevendo e planejando ações.

Quanto a origem dos dados a pesquisa se caracteriza como documental visto que se vale de dados já colhidos para outros fins conforme explica Mattar (2008). Nesse sentido, foram feitos levantamentos em bancos de dados da empresa, como registros de vendas, balanços, dentre outros. Ao mesmo tempo, se caracteriza como de campo visto que a partir do contato do pesquisador com os envolvidos no processo foram sendo construídos entendimentos sobre a realidade da empresa, contemplando a coleta de dados primários no sentido atribuído por Mattar (2008).

\footnotetext{
${ }^{1}$ THIOLLENT, M. Metodologia da pesquisa-ação. São Paulo: Cortez, 2000.

${ }^{2}$ Idem
} 
Desta forma, uma vez que os dados vão sendo manipulados ao longo do processo de pesquisa, os procedimentos serão esclarecidos concomitantemente com a apresentação e análise que será feita na seção seguinte deste artigo.

\section{ADMINISTRAÇÃO ESTRATÉGICA NA AGÊNCIA X}

Para a implantação do BSC na Agência X os pesquisadores, com especialização no segmento de turismo e conhecedores da metodologia incorporaram-se a organização, a fim de elaborar os procedimentos necessários aos interesses da empresa, melhorar seu desempenho, e dos pesquisadores, aumentar e disseminar o conhecimento.

Como primeira etapa, os pesquisadores realizaram um levantamento de dados e informações, contemplando todos os departamentos da empresa, ocupando um período de 3 meses. Para a coleta dos dados, a metodologia envolveu momentos de observação direta, ao verificar in loco as ações dos colaboradores, momentos de acesso e revisão de documentos e registros financeiros, contábeis, comerciais, procedimentos operacionais, administrativos e de recursos humanos. Além disso, a fim de obter informações para compreender o cenário com um máximo de profundidade, foram realizadas entrevistas com a alta-direção (diretoria), gerentes dos departamentos, focando questões pertinentes à gestão, necessidades, panorama do clima organizacional e os resultados atuais e esperados. Terminado o levantamento, os dados, resultados da auditoria e entrevistas, foram analisados com base nos indicadores financeiros e de mercado, a fim de obter as principais demandas da empresa em relação aos seus negócios, e tabulados e alocados pelos pesquisadores em cada uma das perspectivas do BSC, conforme pode ser observado na Tabela 1.

TABELA 1 - RESULTADOS DO LEVANTAMENTO

\begin{tabular}{ll}
\hline PERSPECTIVA & DEMANDA: RESULTADOS OBTIDOS \\
\hline \multirow{2}{*}{ Financeira } & - Baixa rentabilidade \\
& - Alta inadimplência \\
& - Altos custos \\
\hline \multirow{3}{*}{ Clientes } & - Falta de relacionamento com os clientes \\
& - Falta de estratégias de Marketing \\
& - Alto índice de reclamação dos clientes \\
\hline
\end{tabular}

Continua... 
Continuação...

\begin{tabular}{ll}
\hline & - Excesso de retrabalho \\
& - Falta de métricas de metas \\
& - Demora de retorno as solicitações \\
& - Inexistência de um sistema de BackOffice. \\
& - Falta de procedimentos \\
\hline & - Desmotivação da equipe de colaboradores \\
& - Alto índice de turnover \\
Pessoas & - Baixa retenção de capital intelectual \\
& - Falta de capacitação \\
\hline
\end{tabular}

Fonte: Pesquisa de campo, 2013.

Com base nestes dados foram iniciadas as etapas para aplicação da metodologia a fim de construir o BSC conforme Kaplan e Norton (1997). Dada a complexidade envolvida, pois como visto, é um processo dinâmico, as fases serão discutidas e apresentadas individualmente, pois didaticamente, facilita a compreensão do leitor.

Desta forma, uma primeira etapa correspondeu a formação de grupos de discussão para apresentar os resultados obtidos (Tabela 1) de forma que em conjunto fossem compreendidos e possibilitassem o delineamento do(s) objetivo(s) a $\operatorname{ser}(\mathrm{em})$ perseguidos(s) em curto, médio e longo prazo, abrangendo toda a organização. Estes grupos de discussão foram compostos pelos pesquisadores e diretoria. Para a completa análise foram realizados em três encontros, de forma que todos os pontos foram sistematicamente analisados. Como instrumento para dissecar cada fator foi utilizado o Diagrama de Ishikawa ${ }^{4}$ (LAS CASAS, 1997). Para cada uma das demandas levantadas, foram elaborados diagramas de causa e efeito com o envolvimento dos participantes no projeto. Desta forma foi possível identificar, dentre todas as demandas levantadas (Tabela 1), as que mais impactavam em suas relações com as demais demandas.

Ao se analisar os dados verificou-se que um objetivo a ser perseguido tinha influência ou era influenciado por outros. A fim de explicitar a situação, um aspecto a ser melhorado correspondeu a desmotivação dos funcionários da empresa, a qual advinha da falta de estratégias de marketing, e também da falta de capacitação dos colaboradores e que impactava na falta de relacionamento com o cliente e na inexistência de procedimentos para tratar as reclamações, o que por fim, resultava na

\footnotetext{
${ }^{3}$ Relação entre o número de admissões e demissões ou à taxa de substituição em determinado período.

${ }^{4}$ O Diagrama de Ishikawa também é conhecido no âmbito da qualidade como diagrama de causa e efeito (LAS CASAS, 1997).
} 
baixa rentabilidade nos resultados financeiros da empresa. Desta forma, ficou estabelecido em comum acordo que o objetivo a ser tratado (objetivo de curto prazo), após esta etapa, seria o aumento da rentabilidade em até $7 \%$ em relação ao valor vigente.

Seguindo a metodologia adotada, tomando-se por parâmetro as discussões e consensos entre os grupos de trabalho, para cada uma das perspectivas do BSC (pessoas, processos, clientes e financeiro) foram elaborados objetivos específicos, os quais foram justificados pelos envolvidos na análise, resultando nos dados constantes da Tabela 2, os quais foram sintetizados no Mapa Estratégico mostrado na Figura 1.

TABELA 2 - OBJETIVOS DE CURTO PRAZO

\begin{tabular}{|c|c|c|}
\hline Perspectivado BSC & Ação e objetivo & Justificativa \\
\hline Pessoas & $\begin{array}{l}\text { Aumento do número } \\
\text { de treinamento para os } \\
\text { colaboradores. }\end{array}$ & $\begin{array}{l}\text { Para a agência X conseguir atingir seus objetivos } \\
\text { estratégicos, seria fundamental contar com } \\
\text { profissionais capacitados, pois a qualificação do } \\
\text { empregado gera consequentemente melhoria de } \\
\text { produtividade e um grande diferencial para o negócio. }\end{array}$ \\
\hline Processos & $\begin{array}{l}\text { Redução do número } \\
\text { de não conformidades } \\
\text { de procedimentos } \\
\text { operacionais }\end{array}$ & $\begin{array}{l}\text { A agência X precisava estabelecer metas para garantir } \\
\text { sua sobrevivência, através de um plano estratégico, que } \\
\text { garantisse a correção das não conformidades. Atuando } \\
\text { nas causas das não conformidades elas não ocorrem, e } \\
\text { a empresa segue seu curso normal, sem gastar tempo e } \\
\text { recurso em correções. }\end{array}$ \\
\hline Clientes & $\begin{array}{l}\text { Redução do índice de } \\
\text { reclamação dos } \\
\text { clientes }\end{array}$ & $\begin{array}{l}\text { Na agência X, os motivos de reclamações dos clientes } \\
\text { aconteciam por diversas razões, e algumas delas } \\
\text { estavam fora do alcance de serem tratadas, } \\
\text { independentemente do tamanho da organização. Ações } \\
\text { proativas devem ser tomadas por parte da alta-direção } \\
\text { para redução das reclamações e melhoria do nível de } \\
\text { satisfação dos clientes. }\end{array}$ \\
\hline Financeiro & Redução dos custos & Redução de $30 \%$ dos custos fixos da agência. \\
\hline
\end{tabular}

Fonte: Pesquisa de campo, 2013. 
FIGURA 1- MAPA ESTRATÉGICO EMPRESA X - BSC

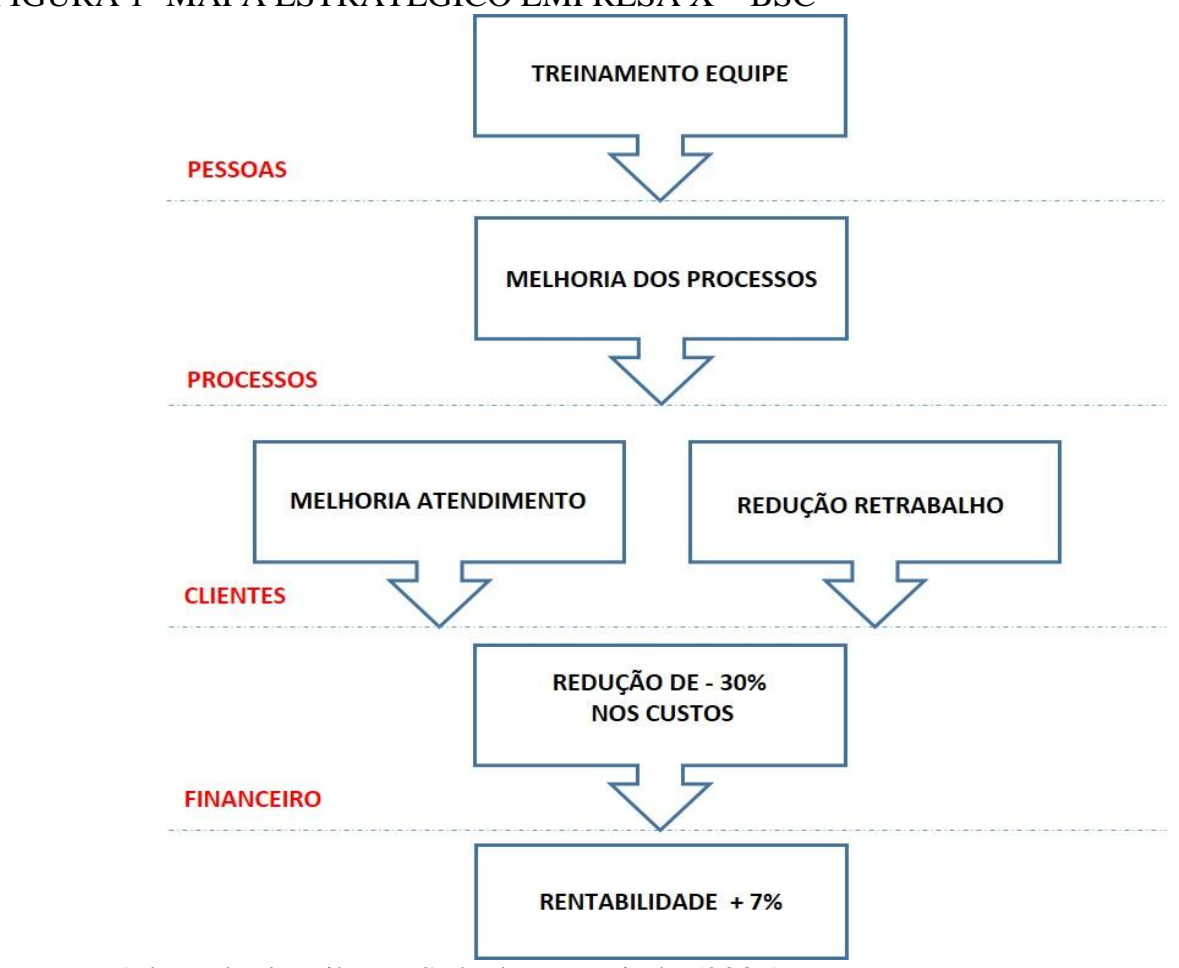

Fonte: Adaptado de Hikage, Spínola e Laurindo (2006).

Para a perspectiva de pessoal estabeleceu-se o objetivo de treinamento, visto que a qualificação é um ponto chave para o sucesso do empreendimento dada a especificidade do serviço. No tocante ao processo, a redução das não conformidades, no que diz respeito aos clientes a redução de reclamações e na perspectiva de custos a redução de custos conforme demonstrado na Figura 1.

Para atender os objetivos propostos a agência de viagens estudada programou treinamento para os níveis operacionais e táticos da empresa, a fim de garantir um maior conhecimento das funções e aprimorar as habilidades da equipe. Foram definidos 4 treinamentos, com a finalidade de atender às dimensões de qualidade em serviços, apresentados por Las Casas (1997), conforme disposto na Tabela 3.

Cada treinamento abordou um tema específico, que atendesse a uma ou mais dimensões em qualidade de serviços (Tabela 3). O plano de treinamento elaborado contemplou os seguintes temas: marketing pessoal; processos internos; marketing de atendimento e marketing de pós-vendas. Após a participação no treinamento, durante a semana e a jornada de trabalho, os funcionários receberam acompanhamento e reforço do aprendizado concedido pelos pesquisadores, de forma individual, concomitante ao 
desempenho de suas tarefas, no momento em que os problemas e dificuldades aconteciam. Desta forma atendendo aos preceitos de interação apontada pela metodologia da pesquisa-ação.

TABELA 3 - DIMENSÃO TRATADA NOS TREINAMENTOS

\begin{tabular}{l|l}
\hline \multicolumn{1}{c|}{ Dimensões } & \multicolumn{1}{c}{ Qualidade dos serviços } \\
\hline Confiabilidade & $\begin{array}{l}\text { Aumentar a qualidade dos serviços prestados aos clientes de forma a fornecer } \\
\text { o que fosse necessário, de maneira segura e precisa. }\end{array}$ \\
\hline Segurança & $\begin{array}{l}\text { Otimizar a habilidade dos funcionários na execução de suas atividades, } \\
\text { conhecimento dos serviços e produtos oferecidos e processos bem definidos, } \\
\text { que proporcionassem segurança e confiança ao cliente. }\end{array}$ \\
\hline Aspectos tangíveis & $\begin{array}{l}\text { Melhorar os aspectos físicos como: estrutura, equipamentos, layout e } \\
\text { aparência dos funcionários. }\end{array}$ \\
\hline Empatia & $\begin{array}{l}\text { Capacitar os funcionários a desenvolver a empatia, de se colocar no lugar do } \\
\text { cliente, proporcionando melhoria na receptividade dispensada aos clientes no } \\
\text { atendimento e oferta de serviços com presteza. }\end{array}$ \\
\hline
\end{tabular}

Fonte: Adaptado de Las Casas (1997).

A partir do plano de treinamento executado, seguiu-se para a próxima etapa do BSC (KAPLAN; NORTON, 1997), realização de reunião com a equipe estratégica e alta direção, para a definição dos indicadores de mensuração relativos a cada uma das perspectivas (Tabela 2), com o resultado esperado. Após a reunião, para cada perspectiva, ficaram definidos os indicadores e o prazo para sua mensuração, conforme apresentado na tabela 4.

A auditoria foi determinada como mensal nos três primeiros meses, sendo que após esse período, ocorreu trimestralmente, até completar um ano. Para todo este processo, manteve-se como metodologia a observação direta, levantamento de documentos e registros financeiros, contábeis, comerciais, procedimentos operacionais, administrativos e de recursos humanos, havendo a interação entre pesquisadores e o ambiente em que ocorria a investigação.

Com a definição do plano de ação e indicadores, iniciou-se a etapa de divulgação a equipe (KAPLAN; NORTON, 1997). Os diretores realizaram uma reunião com toda a equipe para apresentar o planejamento estratégico pelo BSC, explicando cada etapa, ação e indicadores, bem como discutiram os objetivos e justificaram cada um deles.

A equipe de pesquisadores permaneceu na empresa pelos três meses iniciais, do planejamento estratégico, acompanhando cada um dos funcionários, gerentes e diretoria, 
valendo-se da ferramenta PDCA a fim de tratar problemas e reforçar a capacitação dos colaboradores da empresa.

TABELA 4 - INDICADORES DE PERFORMANCE E TEMPO DE MENSURAÇ̃̃O

\begin{tabular}{|c|c|c|}
\hline Perspectiva do BSC & Indicador & Tempo de mensuração \\
\hline Pessoas & $\begin{array}{l}\text { Indicador carga horária em treinamento e avaliação de } \\
\text { eficácia em treinamento (ISO 10015) }\end{array}$ & Mensalmente (30 dias) \\
\hline Processos & $\begin{array}{l}\text { \% de não conformidade pelo determinado período: } \\
\text { calculado pela quantidade de bilhetes de viagens que } \\
\text { foram reemitidos e, nas alterações realizadas nos } \\
\text { pacotes de viagens já fechados, que não por } \\
\text { solicitação do cliente. Considera-se } 0 \text { sendo perfeito, } 1 \\
\text { tolerável e acima disso recomenda-se avaliação do } \\
\text { gestor direto junto ao operador. }\end{array}$ & Mensalmente (30 dias) \\
\hline Clientes & $\begin{array}{l}\text { \% de reclamações } x \text { quantidade de clientes atendidos, } \\
\text { considerando } 0 \text { sendo perfeito, } 1 \text { tolerável e acima } \\
\text { disso recomenda-se avaliação do gestor direto junto ao } \\
\text { operador. }\end{array}$ & Mensalmente (30 dias) \\
\hline Financeiro & $\begin{array}{l}\text { Foram previstas } 3 \text { escalas de redução, sendo que cada } \\
\text { escala está associada a um mês com uma estimativa de } \\
10 \% \text { de redução. Após o terceiro mês, seria um total } \\
\text { de } 30 \% \text { de redução. No quarto mês, o indicador } \\
\text { deveria estabilizar em } 30 \% \text { de redução e, mantido nos } \\
\text { meses subsequentes. }\end{array}$ & Mensalmente (30 dias) \\
\hline
\end{tabular}

Fonte: Pesquisa de campo, 2013.

No primeiro mês, foram constatados os seguintes resultados, a equipe se apresentou motivada, houve melhora do clima organizacional, aumentou o engajamento dos funcionários na melhoria da execução de suas atividades e, a redução do absenteísmo. Quanto aos processos, existia um percentual de $12 \%$ de tarefas identificadas como não conformidade que no primeiro mês reduziu para 9,8\%. A redução dos custos não apresentou uma efetividade, justificados pelos investimentos dispensados ao treinamento e monitoramento. A redução atingiu 7,5\% enquanto o esperado era de $10 \%$. A média de reclamações dos clientes via canais de comunicação estabelecidos, desconsiderando as reclamações informais, era de 21 reclamações mês, as quais foram reduzidas para 19.

A próxima avaliação aconteceu ao final do segundo mês. Os resultados, relacionados à perspectiva de pessoas e processos, mantiveram-se como no primeiro mês. A redução dos custos, perspectiva financeira melhorou, ao todo se reduziu 10,2\%, quando o esperado era $10 \%$. Na perspectiva de clientes, as reclamações reduziram para 14, quando eram 21 no início e, 19 no primeiro mês da implantação do BSC. 
Novamente os resultados foram devidamente tratados e validados com a diretoria e após, apresentados a toda a equipe.

No terceiro mês, um operador solicitou a demissão por motivos de viagem familiar, desestabilizando a homogeneidade da equipe, porém foi substituído em tempo por outro profissional que foi devidamente treinado. Os custos reduziram somente $10,1 \%$, devido às custas de rescisão do contrato. O índice de reclamação do cliente baixou, ainda mais para 9 reclamações ao mês $(-42,85 \%)$. Os resultados quanto a perspectiva de pessoas se mantiveram iguais e na de processo o número de nãoconformidades reduziu mais $11 \%$.

Para os meses subsequentes, ficou estabelecido em reunião com a diretoria, que os resultados do terceiro mês deveriam ser mantidos, com oscilação máxima prevista de uma escala de $+10 \%$ e $-10 \%$.

Do quarto ao décimo segundo mês, a equipe de pesquisadores permaneceu acompanhando o planejamento estratégico, de forma remota com alguns momentos presenciais. As visitas técnicas somaram-se, aproximadamente, três horas semanais. Nesta etapa continuaram a executar as auditorias, análise e avaliação do planejamento estratégico e seus indicadores, valendo-se da ferramenta do PDCA e, propiciando a possibilidade de correções quando foram necessárias.

Durante este período as reuniões com a equipe geral, para apresentação de resultados, aconteceram trimestralmente. Ao final do décimo segundo mês, considerouse finalizado o projeto do planejamento estratégico, sendo que a equipe estava apta a continuar os procedimentos sem o acompanhamento sistemático dos pesquisadores. Os resultados foram auditados, analisados, apresentados e validados com a diretoria. Subsequentemente, em uma reunião específica de entrega de resultados, divulgado a toda a equipe.

Dentre os objetivos específicos designados no início dos trabalhos, verificou-se melhoria na rentabilidade da empresa em 5\%. Este resultado foi obtido em quatro perspectivas, conforme se demonstra na Tabela 5.

Com base nos dados, verificou-se que o BSC se constituiu em uma eficiente ferramenta, pois conseguiu envolver toda a empresa em um único objetivo que permeia as 4 perspectivas (aprendizado e crescimento, processos internos, clientes e financeiro) que permitem uma visão macro de toda organização. 
TABELA 5 - RESULTADOS ALCANÇADOS COM O PLANEJAMENTO ESTRATÉGICO NA AGÊNCIA X

\begin{tabular}{|c|c|c|}
\hline Perspectiva do BSC & Resultados esperados & Resultados obtidos \\
\hline Pessoas & $\begin{array}{l}\text { Indicador carga horária em treinamento e } \\
\text { avaliação de eficácia em treinamento (ISO } \\
\text { 10015) }\end{array}$ & $\begin{array}{lll}92 \% \text { de } & \text { carga horária de } \\
\text { treinamento } & \text { e } 96 \% \text { de eficácia } \\
\text { atingida. } & & \end{array}$ \\
\hline Processos & $\begin{array}{l}\text { \% de não conformidade pelo determinado } \\
\text { período: calculado pela quantidade de } \\
\text { bilhetes de viagens que foram reemitidos x } \\
\text { alterações realizadas nos pacotes de viagens } \\
\text { já fechados, que não por solicitação do } \\
\text { cliente. Considera-se } 0 \text { sendo perfeito e } 1 \\
\text { tolerável. }\end{array}$ & $0,3 \%$ de não conformidades \\
\hline Clientes & $\begin{array}{l}\% \text { de reclamações } x \text { quantidade de clientes } \\
\text { atendidos, considerando } 0 \text { sendo perfeito, } 1 \\
\text { tolerável. }\end{array}$ & $\begin{array}{l}0,9 \text { de reclamações de clientes } x \\
\text { clientes atendidos }\end{array}$ \\
\hline Financeiro & $30 \%$ de redução de custos & $29,4 \%$ de redução \\
\hline
\end{tabular}

Fonte: Pesquisa de campo, 2013.

Com base no estudo realizado na agência de viagem $X$, verificou-se que com a aplicação da ferramenta, obteve-se uma melhoria na gestão, aumento da produtividade representada pela redução de custos em $29,4 \%$ e a melhoria da qualidade dos serviços com $0,9 \%$ de reclamações dos clientes atendidos, contribuindo de maneira geral, para o aumento da rentabilidade em 5\%. Os resultados analisados pelos indicadores, evidenciam a melhora no desempenho operacional, que teve uma evolução após a realização do trabalho de consultoria em gestão estratégias na empresa com a aplicação do BSC.

\section{CONSIDERAÇÕES FINAIS}

$\mathrm{Na}$ atualidade o mercado está se tornando cada vez mais competitivo e globalizado, exigindo que as organizações repensem seus processos e adaptem-se a essa nova realidade. Portanto faz-se necessária a utilização de ferramentas que permitam gerenciar a organização de forma profissional e precisa. Uma forma de atender a essa demanda é o uso do BSC como um sistema de mensuração, alinhamento e controle estratégico de gestão.

Quanto ao alcance dos objetivos considera-se que o central foi atendido, visto que foi possível identificar os procedimentos adotados pela empresa para a aplicação do instrumento BSC para o gerenciamento da estratégia. Verificou-se que a ferramenta 
seria bastante útil no sentido de direcionar as ações da empresa, no entanto, para a análise foram necessários instrumentos auxiliares específicos como o diagrama de causa e efeito. Além disso, na implementação o PDCA foi de grande valia como instrumento auxiliar.

No tocante ao aprofundamento dos conhecimentos teóricos foi auferido através da revisão bibliográfica, o qual foi ampliado por meio da interação com os agentes da empresa nos momentos de sua aplicação. Nesse caso, obtiveram-se mudanças, tanto de parte da organização em termos de procedimentos e comportamentos adequados a melhoria do posicionamento da empresa, como de parte dos investigadores, no sentido de comprovar na prática a teoria.

Assim os demais objetivos foram alcançados, com a descrição das etapas e a descrição de todo o processo, de forma que outros possam com mais facilidade aplicar o BSC em empresas. No caso das agências de viagens, considera-se que, podem utilizar o BSC como ferramenta de gestão estratégica, especialmente por não focarem apenas nos seus ganhos financeiros, mas atuando sobre as quatro perspectivas ditadas pela metodologia.

Outras pesquisas neste contexto podem ser realizadas, especialmente no que tange ao clima organizacional da empresa onde se implanta o BSC. Observou-se o ganho econômico da empresa, porém aprofundar conhecimentos quanto ao comportamento humano na organização seria de grande valia para se aprofundar a discussão quanto a aplicação da ferramenta na gestão estratégica de organizações turísticas.

\section{REFERÊNCIAS}

ANDRADE, D. C. T.; CASTRO, C. G.; OLIVEIRA, D. R.; SANTOS, A. C. O turismo em pequenas cidades brasileiras: possíveis soluções para o setor sob a ótica das relações interorganizacionais. Revista de Administração da UEG, Aparecida de Goiânia, v. 3, n. 2, jul./dez. 2012.

ANJOS, F. A.; LIMBERGER, P. F.; ANJOS, S. J. G.; DOMARESKI, T. C. Contribuciones de la gestión del conocimiento a los servicios turísticos: Estudio en una agencia de viajes. Estudios y Perspectivas en Turismo, Ciudad Autónoma de Buenos Aires, v. 20, n. 3, jun. 2011. 
BORGES, A. L.; GUARDIA, M. S. As agências de viagens e turismo: um estudo das publicações em periódicos de turismo entre os anos 2006-2011. Turismo: Estudos e Práticas - UERN, Mossoró/RN, v. 1, n. 2, jul./dez. 2012.

BRASIL. Ministério do Turismo. Documento Referencial Turismo no Brasil 20112014. Brasília: MTur, 2011. Disponível em: <http://www.dadosefatos.turismo.gov.br/export/sites/default/dadosefatos/outros_estudo s/downloads_outrosestudos/Turismo_no_Brasil_2011__2014_sem_margem_corte.pdf>. Acesso em: 19/08/2014.

DANTAS, R. G.; GOSLING, M.; COELHO, M. F. O processo de recuperação de serviços em agências de turismo através da abordagem do sistema sócio-técnico. Turismo e Sociedade, Curitiba/PR, v. 6, n. 2, p. 440-461, abril, 2013.

FERRAZ, J. C.; KUPFER, D.; HAGUENAUER, L. Made in Brazil: desafios competitivos para a indústria. Rio de Janeiro: Campus, 1995.

GIL, A. C. Como elaborar projetos de pesquisa. São Paulo: Atlas, 2002.

GODOY, A. S. Pesquisa qualitativa: tipos fundamentais. ERA, São Paulo, v. 35, n. 3, p. 20-29, mai./jun. 1995.

GORI, R. M. A. Observação participante e pesquisa-ação: aplicações na pesquisa e no contexto educacional. Revista Itinerarius Reflectionis. Jataí, Goiás, v. 1 n. 2, jan./jul., 2006.

GORNI, P. M.; DREHER, M. T.; MACHADO NETO, D. D. P. Inovação em serviços turísticos: a percepção desse processo em agências de viagens. Revista Acadêmica Observatório de Inovação do Turismo. Rio de Janeiro, v. 4, n. 1, p. 1-14, mar. 2009.

HIKAGE, O. K.; SPINOLA, M. M.; LAURINDO, F. J. B. Software de balanced scorecard: proposta de um roteiro de implantação. Produção, v. 16, n. 1, p. 140-160, 2006.

KAPLAN, R. S.; NORTON, D. P. A estratégia em ação: balanced scorecard. Rio de Janeiro: Elzevier, 1997.

Organização orientada para a estratégia: como as empresas que adotam o balanced scorecard prosperam no novo ambiente de negócios. 11. ed. Rio de Janeiro: Campus, 2001. 411 p.

LAS CASAS, A. L. Qualidade total em serviços: conceitos, exercícios e casos práticos. 2. ed. São Paulo: Atlas, 1997.

MALHEIROS, T.; COUTINHO, S. M. V; PHILIPPI JR., A. Indicadores de sustentabilidade: uma abordagem conceitual. In: MALHEIROS, T.; PHILIPPI JR., A. (Orgs.) Indicadores de sustentabilidade e gestão ambiental. Barueri, SP: Manole: $p$. 31-76, 2012. 
MATTAR, F. N. Pesquisa de Marketing edição compactada. São Paulo: Atlas, 2008.

MARCONI, M. A.; LAKATOS, E. M. Técnicas de Pesquisa. São Paulo: Atlas, 2006.

MENEZES, V. O.; STAXHYN, A. P. Consultor de viagens: o profissional do novo Mercado turístico. Turismo e Sociedade, Curitiba/PR, v. 4, n 2, p. 381-397, outubro, 2011.

OLIVEIRA, D. P. R. de. Planejamento estratégico: conceitos, metodologia e práticas. 29 ed. São Paulo: Atlas, 2011.

OLVE, N. G.; ROY, J.; WETTER, M. Condutores da performance: um guia prático para o uso do balanced scorecard. Rio de Janeiro: Qualitymark, 2001.

PORTER, M. Estratégia Competitiva: técnicas para análise de indústrias e da concorrência. Rio de Janeiro: Campus, 1989.

QUEIROZ, D. T.; VALL, J.; SOUZA, A. M. A.; VIEIRA, N. F. C. Observação participante na pesquisa qualitativa: conceitos e aplicações na área da saúde. In: Revista Enfermagem UERJ, Rio de Janeiro, 15 (2), 276-283, abr./jun. 2007.

RANGEL, A. S.; BRAGA, D. C. Integración vertical y desintermediación: La realidad de las agências de viaje en Brasil. In: Estudios y Perspectivas en Turismo. Ciudad Autónoma de Buenos Aires, v. 21, n. 6, dic. 2012.

RUIZ, T.; GÂNDARA, J. A relação entre o Planejamento Urbano e a Competitividade dos Destinos Turísticos. Revista Brasileira de Pesquisa em Turismo. São Paulo, 7 (2), p. 260-280, mai./ago. 2013.

SOUTO-MAIOR, J. Planeação estratégica e comunicativa. João Pessoa: Editora universitária da UFPB, 2012.

SWARBROOKE, J. Turismo sustentável: setor público e cenários geográficos, v. 3. São Paulo: Aleph, 2000.

THOMPSON, A.; STRICKLAND, III J. Planejamento estratégico: elaboração, implementação e execução. São Paulo: Pioneira, 2000.

WRIGHT, P.; KROLL, M. J.; PARNELL, J. Administração estratégica: conceitos. São Paulo: Atlas, 2011.

YIN, R. K. Estudo de caso: planejamento e métodos. Porto Alegre: Bookman, 2010.

Recebido em: 26-05-2015.

Aprovado em: 25-06-2015. 